\title{
PREGÃO PRESENCIAL E ELETRÔNICO SOB A ÓTICA DOS GESTORES PÚBLICOS MUNICIPAIS
}

\author{
PRESENCIAL AND ELECTRONIC TRADING FROM THE VIEWPOINT OF MUNICIPAL \\ PUBLIC MANAGERS
}

\author{
Cristiano Sausen Soares ${ }^{1}$ \\ Universidade Federal de Santa Maria \\ cristianocontador@hotmail.com
}

\author{
Emanuele Marcuzzo \\ Universidade Franciscana \\ manu_marcuzzo@outlook.com
}

\section{RESUMO}

O estudo tem por objetivo verificar as características do pregão presencial e eletrônico, sob a ótica dos gestores públicos municipais, por meio de uma pesquisa qualitativa, descritiva, com o uso de levantamento para coleta de dados, sendo aplicados questionários aos gestores públicos dos municípios da região central do Rio Grande do Sul, com base nas características identificadas na literatura. Os resultados evidenciam como vantagens do pregão presencial: agilidade, transparência e economia aos cofres públicos; e desvantagens: menor concorrência, seções tumultuadas e lentidão no processo. No pregão eletrônico, evidencia-se como vantagens: agilidade, eficiência e economicidade; e desvantagens: qualidade dos produtos, demora na entrega e dependência da internet. Conclui-se que as características identificadas na literatura são corroboradas empiricamente pelos gestores públicos. No entanto, mesmo com a indicação preferencial de uso do pregão eletrônico, este ainda é restrito devido a questões estruturais.

Palavras-chave: Administração Pública. Licitação. Pregão Presencial. Pregão Eletrônico.

\section{ABSTRACT}

The study aims to verify the characteristics of the face-to-face and electronic auctions, from the perspective of municipal public managers, through a qualitative, descriptive research, using a survey to collect data, and questionnaires were applied to public managers in the municipalities of the city central region of Rio Grande do Sul, based on the characteristics identified in the literature. The results show that the advantages of face-to-face trading are: agility, transparency and economy for public coffers; and disadvantages: less competition, tumultuous sections and slowness in the process. In electronic trading, the following are evidenced as

\footnotetext{
${ }^{1}$ UFSM - Av. Roraima, no 1000 - Cidade Universitária, CCSH - Prédio 74C, Sala 4346

Bairro Camobi, Santa Maria/RS - Cep.: 97.105-900.

* Estudo apresentado no III CIDESP (Congresso Internacional de Desempenho do Setor Público), sendo incorporadas sugestões e discussões.
} 
advantages: agility, efficiency and economy; and disadvantages: quality of products, delay in delivery and dependence on the internet. It is concluded that the characteristics identified in the literature are supported empirically by public managers. However, even with the preferred indication of using the electronic auction, it is still restricted due to structural issues.

Keywords: Public Administration. Bidding. On-Site Trading. Electronic Trading.

\section{INTRODUÇÃ̃O}

A sociedade brasileira necessita de maior transparência nos atos dos gestores públicos para auxiliar no combate à corrupção. Dentre tais atos, Sobral e Neto (2020) destacam as compras públicas, tendo em vista que a prestação de serviços aos cidadãos, muitas vezes, depende da aquisição de bens e outros insumos no mercado privado, cujos processos de compra, via de regra, ocorrem por meio de licitação e contratos públicos.

Conforme Meirelles (2007, p. 25), "licitação é o procedimento administrativo mediante o qual a Administração Pública seleciona a proposta mais vantajosa para o contrato de seu interesse". As compras públicas são regidas pela Lei Federal n 8.666/1993, instituída aos órgãos públicos da administração direta e indireta, federal, estadual e municipal. Conforme essa norma, foram instituídas diferentes modalidades de licitação, cujas características e ritos são distintos entre si. No entanto, a Lei $\mathrm{n}^{\mathrm{o}}$ 10.520/2002 instituiu a modalidade Pregão, tendo como foco a aquisição de bens e serviços comuns, na qual a disputa entre os licitantes é realizada em sessão pública (NIEBUHR, 2005). Para Almeida e Sano (2018), a adoção do Pregão como modalidade licitatória tem como propósito aprimorar a eficiência do sistema de compras públicas, dar maior transparência e instigar a competição entre os fornecedores.

A modalidade pregão, inicialmente desenvolvida na forma presencial, evoluiu para a forma eletrônica com o uso da tecnologia da informação (VASCONCELOS, 2006) e apoiada na Teoria dos Leilões (ALMEIDA; SANO, 2018). Conforme Faria et al. (2011), no Pregão presencial os licitantes devem estar presentes em seção pública, apresentando suas propostas e ofertando lances de forma verbal, enquanto no Pregão eletrônico a disputa pelo fornecimento de bens ou serviços comuns é realizada em sessão pública, via internet e utilizando um sistema que promove a comunicação entre os licitantes e o setor público.

Regulamentado pelo Decreto $\mathrm{n}^{\circ} 5.450 / 2005$, o pregão eletrônico apresenta algumas vantagens à Administração Pública, como agilidade e celeridade no processo licitatório, aumento da competitividade e, principalmente, redução de custos ao órgão público que o executa (FARIA et al., 2011). Com tais características, os Tribunais de Contas (órgãos de fiscalização externa da união, estados e municípios) indicam preferencialmente a implantação do pregão eletrônico como prática para aquisições aos entes públicos, devendo ser justificado quando utilizada outra modalidade. Apesar dessa indicação, alguns municípios, principalmente aqueles de menor porte, podem enfrentar dificuldades para implantação e uso do Pregão eletrônico, mantendo o pregão presencial como forma de adquirir os insumos necessários. Por este motivo, torna-se relevante conhecer a percepção dos agentes públicos que executam as atividades de compras nesses municípios, quanto as características do pregão, contribuindo à literatura acerca do tema e à prática de compras no setor público.

Assim, considerando as formas de execução do pregão (presencial e eletrônico), apresenta-se a questão: quais são as características das compras públicas na modalidade pregão, nas formas presencial e eletrônica, sob a ótica dos gestores públicos municipais? Para tanto, o objetivo geral do estudo é verificar as características do pregão presencial e eletrônico, sob a ótica dos gestores públicos municipais. 
De acordo com Sobral e Neto (2020), é importante investigar os ritos e fundamentos jurídicos e administrativos do pregão, como modalidade de licitação que visa contribuir para aquisições mais vantajosas aos entes públicos, garantindo maior economicidade e atenção ao interesse coletivo. Nessa linha, são identificados estudos anteriores na literatura acerca do tema, como a pesquisa de Faria et al. (2011) que analisou de forma comparativa os pregões presenciais e eletrônicos, entre duas entidades públicas distintas (Prefeitura de Viçosa e a Universidade Federal de Viçosa), quanto ao custo e tempo, concluindo que o pregão eletrônico é o mais vantajoso. Contudo, o presente estudo se diferencia dos demais ao considerar as características do pregão identificadas na literatura, confrontando com a percepção dos gestores públicos que utilizam o pregão para realização dos processos de compras.

Assim, o estudo se justifica pela necessidade de auxiliar os gestores públicos com informações acerca das características do pregão, nas formas presencial e eletrônica, bem como suas vantagens e desvantagens sob a ótica dos gestores públicos municipais envolvidos nesses processos, visando maior eficácia do gasto público e, consequentemente, melhoria na gestão pública. De acordo com Almeida e Sano (2018), a função de compras públicas enfrenta desafios quanto a maior celeridade nos processos e demais benefícios. Nesse contexto, ao considerar suas características, os gestores podem melhor planejar as ações de compras na modalidade pregão, evitando situações indesejadas e o bom andamento dos processos. Além disso, o estudo pode contribuir à sociedade ao oportunizar o debate acerca dos atos praticados nas compras públicas municipais, visando o melhor desempenho do setor. Espera-se que o estudo possa auxiliar os gestores e agentes públicos no planejamento de ações e revelar necessidades de ajustes operacionais para atendimento à legislação que norteia o pregão.

\section{REFERENCIAL TEÓRICO}

\subsection{A contabilidade governamental e as compras públicas}

A Contabilidade pública vem passando por importantes transformações, nos últimos anos, tanto em decorrência dos processos de convergência às normas internacionais, quanto em função das demandas da sociedade em relação a eficiência. Por ser considerada a ciência que estuda o patrimônio público e fornece informações para que as decisões possam ser tomadas (KOHAMA, 2014), a Contabilidade governamental também serve como fonte de dados para seus usuários, possibilitando a comparação e análise da informação contábil nos diferentes níveis de governo, além de auxiliar na avaliação do desempenho da gestão (SILVA, 2003).

Para Kohama (2014), a Administração Pública recorre aos relatórios gerenciais para analisar e monitorar a eficácia de suas ações, proporcionando redução de erros e irregularidades, o que requer atenção com o uso dos recursos públicos e responsabilidade dos seus gestores. Desse modo, a Contabilidade e a Administração Pública estão interligadas para que ambas possam dar respostas à sociedade, sendo estes temas de interesse de todos os cidadãos, principalmente por tratar da utilização do dinheiro público.

Nesse contexto, a informação contábil contribui para dar maior transparência, além de ampliar a capacidade de avaliação do desempenho dos gestores e melhorar o desempenho do setor público (RAUSCH; SOARES, 2010). Por tais razões, a Contabilidade Pública auxilia os gestores nos atos praticados, pois é através das informações fornecidas por ela que a gestão pública verifica a possibilidade de desenvolver suas atividades e, desse modo, propor políticas que atendam as demandas do cidadão.

Contudo, para atender de maneira eficaz as necessidades básicas da sociedade, os agentes públicos devem considerar os elementos da Teoria de Finanças Públicas, 
especificamente receitas e despesas. Ao estudar tais elementos, tem-se o orçamento como importante ferramenta na gestão pública, pois é através dele que será demonstrada a origem e aplicação dos recursos. "O orçamento não é mero documento de caráter contábil ou administrativo, mas sim, poderoso instrumento de política econômica e social que, para sua execução, depende da correta e eficaz alocação dos recursos" (FABRETTI, 2005, p.19).

Os aspectos orçamentários compreendem tanto o Plano Plurianual (PPA), a Lei de Diretrizes orçamentárias (LDO) e a Lei do Orçamento Anual (LOA). A LOA, chamada de orçamento público, é composta pela estimativa das receitas e fixação das despesas (KOHAMA, 2014). A receita orçamentária "corresponde à arrecadação de recursos financeiros autorizados pela LOA e que serão aplicados na realização dos gastos públicos" (SILVA, 2003, p.103). A Lei 4.320/1964, em seu art.11, classifica as receitas orçamentárias entre receitas correntes $\left(\S^{\circ}\right)$ e receitas de capital $\left(\$ 2^{\circ}\right)$. Em relação à despesa, Silva (2003) conceitua como despesa corrente o conjunto de gastos realizados pelos agentes para custear os serviços públicos, enquanto as despesas de capital podem ser descritas como dispêndios efetuados para futuros investimentos.

Antes de praticar qualquer ação, os gestores públicos devem analisar a efetiva situação financeira, acompanhando a execução do orçamento público para realizar seus objetivos. Diferente do setor privado, a Administração Pública não possui autonomia para contratar serviços, adquirir materiais de consumo, alienar e locar bens ou contratar obras, uma vez que os agentes públicos devem observar rigorosamente a legislação que rege tais procedimentos (SCHEREN; WESCINSKI; BARICHELLO, 2017). Para tanto, deve-se observar as normas públicas para aquisições, denominadas como licitações e contratos públicos.

A licitação é um ato administrativo regulamentado pela Lei Federal no 8.666/1993, em atenção ao inciso XXI do art. 37 da Constituição Federal que determina a aquisição de bens e serviços pela Administração Pública por meio de processos licitatórios (BRASIL, 1988). Desta forma, entende-se que a licitação é o mecanismo pelo qual a Administração Pública seleciona a proposta mais vantajosa para futuros contratos de seu interesse, tendo como base o instrumento convocatório estabelecido e demais leis norteadoras (FERNANDES, 2009).

Um dos objetivos da licitação é assegurar isonomia entre os licitantes, observando a preferência pela proposta mais vantajosa (SLOMSKI, 2003). Nesse contexto, quando há interesse na aquisição de bens e contratação de obras e serviços por parte do setor público, é necessário formalizar uma licitação. Logo, é fundamental que esse processo siga todos os trâmites, conforme a legislação vigente, optando pela proposta que atenda aos interesses públicos. Contudo, deve-se observar as particularidades de cada tipo e modalidade.

Para Carvalho Filho (2012), o tipo de licitação está associado ao critério que será empregado para o julgamento das propostas, o qual deverá ser definido em edital, para que os licitantes possam embasar a formulação das ofertas, cujo julgamento deve ser claro e objetivo. Conforme prevê o $\S 1^{\circ}$ do art. 45 da Lei 8.666/1993, os tipos de licitação, exceto na modalidade concurso, são: menor preço; melhor técnica; melhor técnica e preço; e, maior lance ou oferta.

Neste contexto, conforme o art. 22 da Lei $\mathrm{n}^{\circ}$ 8.666/1993, os gestores públicos devem escolher uma das modalidades de licitação para elaborar o instrumento convocatório pertinente com o propósito de efetivar uma contratação. As modalidades apresentadas na referida Lei são: Concorrência; Tomada de Preços; Convite; Concurso; e, Leilão (MEIRELLES, 2007). No entanto, ainda se prevê casos em que a licitação pode ser dispensada ou não exigida, considerando as possíveis razões para aquisições diretas, cujos argumentos para dispensa constam no art. 24 , e no art. 25 são citadas as circunstâncias em que ela é inexigível. "A definição da modalidade de licitação não deve fazer-se apenas em função do valor da contratação. Também deverá tomar-se em vista a complexidade do objeto" (JUSTEN FILHO, 
2004, p.203). Assim, a modalidade deve ser definida considerando basicamente dois aspectos: (i) o que se deseja adquirir, e (ii) a estimativa de custo para a contratação do objeto pretendido.

Além das modalidades previstas na Lei $\mathrm{n}^{\circ}$ 8.666/1993, a Lei $\mathrm{n}^{\circ} 10.520 / 2002$ instituiu a modalidade pregão, destinada ao fornecimento de bens e serviços comuns, em que os licitantes apresentam propostas, por escrito, com lances verbais ou via internet, independentemente do valor estimado para contratação. Para Meirelles (2007), dentre as modalidades de licitação, o Pregão é a mais utilizada no setor público, tendo como principais vantagens: agilidade e redução da burocracia. Complementarmente, Santana e Santos (2012, p.255) argumentam que "a modalidade pregão está em compasso com a finalidade precípua da licitação, que é a de selecionar a proposta mais vantajosa para a Administração, e em consonância com o interesse público", garantindo os princípios constitucionais da licitação.

Além da definição do pregão como modalidade, a Lei $\mathrm{n}^{\circ}$ 10.502/2002 estabelece os procedimentos, ritos e a necessidade de uma equipe de apoio ao pregoeiro, possibilitando que o pregão seja realizado na forma presencial ou eletrônica. Assim, Santos (2008) ressalta que cabe a autoridade competente designar, entre o quadro de servidores do órgão público, o pregoeiro e sua equipe de apoio, cujas incumbências, com base no edital, incluem: recebimento das propostas e acompanhamento dos lances; análise da aceitabilidade e classificação; habilitação e adjudicação do objeto.

\subsection{Pregão presencial}

Conforme Araújo (2006, p. 19), “o pregão presencial é a modalidade de licitação para aquisição de bens e serviços, de natureza comum, instituída no âmbito da União, Estados, Municípios e Distrito Federal”. Complementarmente, Meirelles (2007) diz que no pregão presencial os participantes do certame devem estar presentes no local, hora e data previamente marcada, em seção pública, para apresentação de propostas e lances verbais, conforme edital.

De forma geral, a utilização do pregão presencial nos órgãos públicos motivou diferentes estudos, sendo possível identificar características descritas como vantagens ou desvantagens. No Quadro 1, apresentam-se vantagens e desvantagens do pregão presencial identificadas nos estudos anteriores acerca do tema.

Quadro 1 - Vantagens e desvantagens do pregão presencial conforme a literatura.

\begin{tabular}{|l|l|}
\hline Autores & Vantagens \\
\hline $\begin{array}{l}\text { Niebhur (2005); Ramos, Vargas, } \\
\text { Novicki e Moraes (2016); Soares e } \\
\text { Possobom (2017). }\end{array}$ & $\begin{array}{l}\text { Maior participação de empresas locais e promoção do desenvolvimento } \\
\text { regional. }\end{array}$ \\
\hline $\begin{array}{l}\text { Nunes (2007); Pereira (2014); } \\
\text { Ramos et al. (2016). }\end{array}$ & $\begin{array}{l}\text { Melhor negociação entre os licitantes, tendo em vista a negociação } \\
\text { imediata, pois o vencedor é revelado logo após a análise da } \\
\text { documentação. }\end{array}$ \\
\hline $\begin{array}{l}\text { Nunes (2007); Pereira (2014); } \\
\text { Ramos et al. (2016). }\end{array}$ & $\begin{array}{l}\text { Maior possibilidade de esclarecimentos de dúvidas em relação ao item } \\
\text { proposto no edital. }\end{array}$ \\
\hline $\begin{array}{l}\text { Nunes (2007); Pereira (2014); } \\
\text { Ramos et al. (2016). }\end{array}$ & Não depende de conexão via internet. \\
\hline Autores & Desvantagens \\
\hline $\begin{array}{l}\text { Niebhur (2005); Nunes (2007); } \\
\text { Ramos et al. (2016). }\end{array}$ & Menor concorrência (poucas empresas participantes no processo). \\
\hline $\begin{array}{l}\text { Niebhur (2005); Nunes (2007); } \\
\text { Ramos et al. (2016). }\end{array}$ & $\begin{array}{l}\text { Tumulto durante o certame, espaço físico limitado para a realização do } \\
\text { pregão; Discussões entre os licitantes e a comissão. }\end{array}$ \\
\hline $\begin{array}{l}\text { Niebhur (2005); Nunes (2007); } \\
\text { Ramos et al. (2016). }\end{array}$ & Lentidão do certame. \\
\hline
\end{tabular}

Fonte: Dados da pesquisa. 
Com a evolução tecnológica e as novas formas de comunicação, o pregão evoluiu e a forma eletrônica ganhou maior espaço e relevância. Tal aspecto pode ser comprovado a partir do Decreto Federal $\mathrm{n}^{\mathrm{o}}$ 5.450/2005 que exige em seu art. $4^{\circ}$ que a União execute preferencialmente a modalidade de licitação pregão na forma eletrônica, podendo o pregão presencial ser realizado nos casos em que for comprovada sua inviabilidade.

\subsection{Pregão eletrônico}

O pregão eletrônico se fortaleceu como forma licitatória inovadora, acompanhando as novas tecnologias de informação e seus inúmeros recursos (ALMEIDA; SANO, 2018). Na forma eletrônica, o pregão é a modalidade de licitação que adota o tipo menor preço, sendo realizado quando a disputa pelo fornecimento de bens e serviços comuns, através de sessão pública e por meio de um sistema que promova a comunicação via internet.

Nesse contexto, o pregão eletrônico possibilitou um novo formato de licitação, favorecendo o acesso de todos os interessados, via participação virtual dos envolvidos no certame, podendo ser assistido, em todas as fases e etapas, por qualquer cidadão via internet (ARAÚJO, 2006). Assim, o pregão eletrônico apresenta algumas características atribuídas como vantagens e desvantagens, identificadas na literatura, conforme destacado no Quadro 2.

Quadro 2 - Vantagens e desvantagens do pregão eletrônico conforme a literatura.

\begin{tabular}{|l|l|}
\hline Autores & Vantagens \\
\hline $\begin{array}{l}\text { Fernandes (2009); Faria, Ferreira, } \\
\text { dos Santos, e Silveira (2011); } \\
\text { Bittencourt (2014) }\end{array}$ & Agilidade no processo de compra; \\
\hline $\begin{array}{l}\text { Santana (2009); Faria et al. (2011); } \\
\text { Bittencourt (2014) }\end{array}$ & Eficiência e transparência nas contratações; \\
\hline $\begin{array}{l}\text { Nunes, Lucena e Silva (2007); } \\
\text { Faria et al. (2011); Bittencourt } \\
\text { (2014); Ramos et al. (2016). }\end{array}$ & $\begin{array}{l}\text { O licitante não necessita estar presenta fisicamente, possibilitando o } \\
\text { envio de novos lances e o acompanhamento do processo de forma } \\
\text { virtual. Negociação sem interferência de concorrentes nas cotaços; }\end{array}$ \\
\hline $\begin{array}{l}\text { Fernandes (2009); Santana (2009); } \\
\text { Faria et al. (2011) }\end{array}$ & Economicidade; \\
\hline $\begin{array}{l}\text { Barros (2005); Santana (2009); } \\
\text { Faria et al. (2011) }\end{array}$ & $\begin{array}{l}\text { Grande concorrência, tendo em vista o maior número de participação } \\
\text { de empresas. }\end{array}$ \\
\hline Autores & Desvantagens \\
\hline $\begin{array}{l}\text { Nunes (2007); Souza e Teixeira } \\
\text { (2008); Ramos et al. (2016) }\end{array}$ & $\begin{array}{l}\text { Na maioria das vezes não há entrega dos produtos conforme } \\
\text { estabelecido no edital, em razão da distância das empresas; }\end{array}$ \\
\hline $\begin{array}{l}\text { Nunes (2007); Souza e Teixeira } \\
(2008) ; \text { Ramos et al. (2016) }\end{array}$ & $\begin{array}{l}\text { Durante todo o processo, necessita-se de uma internet de boa } \\
\text { qualidade; }\end{array}$ \\
\hline $\begin{array}{l}\text { Nunes (2007); Souza e Teixeira } \\
\text { (2008); Ramos et al. (2016) }\end{array}$ & \begin{tabular}{l} 
Contato indireto com o fornecedor, dificuldades de negociação; \\
\hline $\begin{array}{l}\text { Nunes (2007); Faria et al. (2011); } \\
\text { Ramos et al. (2016) }\end{array}$
\end{tabular} $\begin{array}{l}\text { Demora para o envio dos documentos de habilitação, visto que os } \\
\text { mesmos devem ser enviados via Correio. }\end{array}$ \\
\hline
\end{tabular}

Fonte: Dados da pesquisa.

Nesse contexto, as formas de realização do pregão, como exposto, apresentam vantagens e desvantagens à Administração Pública. Porém, com o surgimento do pregão na forma eletrônica, houve grande avanço nos procedimentos das modalidades licitatórias, utilizando-se de meios eletrônicos para sua realização. Ademais, percebe-se maior agilidade, competitividade e transparência nos atos administrativos quanto a sua realização, além de maior eficiência e respeito à impessoalidade, princípios básicos que devem ser seguidos em processos licitatórios. Ainda, considera-se a maior abrangência dos licitantes, a fase de lances é mais ágil e oferece maior economia aos cofres públicos. 
Conforme exposto, o pregão, seja na forma presencial ou eletrônica, traz benefícios à Administração Pública, em relação as demais modalidades, cabendo a investigação empírica junto aos agentes públicos que atuam na execução de tais ações, podendo emergir novos elementos para contribuir à discussão.

\section{METODOLOGIA}

A pesquisa se classifica como qualitativa, quanto à abordagem do problema, e descritiva quanto aos objetivos. Para Santos (2007), a pesquisa descritiva observa fatos, registra e interpreta, sem a interferência do pesquisador. Com relação aos procedimentos técnicos, o estudo utiliza a pesquisa bibliográfica e o levantamento do tipo survey. Conforme Santos (1991), a pesquisa bibliográfica visa conhecer e analisar conteúdos científicos sobre um assunto. Neste contexto, a pesquisa bibliográfica visa identificar as vantagens e desvantagens destacadas na literatura, servindo para verificação empírica no levantamento realizado junto aos participantes da pesquisa, quanto às características do pregão presencial e eletrônico.

Para selecionar os artigos científicos relacionados ao tema, foi realizada uma busca na base de dados SPELL (Scientific Periodicals Eletronic Library), com o objetivo de capturar estudos empíricos que utilizam no título, resumo ou palavras chave os termos: pregão presencial e eletrônico. Complementarmente, a mesma busca foi realizada na base de dados do Google acadêmico, no intuito de capturar trabalhos acadêmicos (monografias, dissertações e teses) ainda não publicadas em revistas da área. Ressalta-se que foram descartados os estudos e artigos duplicados. Após a busca inicial, foi utilizado o Proknow-C como processo estruturado para seleção de um Portfólio Bibliográfico (VALMORBIDA; ENSSLIN, 2016), iniciando com a leitura dos títulos encontrados, para identificação daqueles alinhados ao tema, eliminando os artigos desalinhados. Na sequência, procedeu-se a leitura dos resumos, sendo descartados aqueles que tangenciam o tema. Por fim, foi realizada a leitura integral dos artigos identificados, sendo selecionados dez estudos que embasaram a elaboração do instrumento de coleta de dados e a discussão dos resultados. Os estudos estão identificados nas referências deste artigo, com a expressão PB e número sequencial de 1 a 10, em ordem decrescente cronológica de publicação.

O levantamento survey é o meio pelo qual o pesquisador busca informações diretamente com um grupo de interesse, vinculado aos dados que se pretende obter ou informações sobre as características ou opiniões de determinado grupo de pessoas, indicado como representante de uma população-alvo, utilizando um questionário como instrumento de pesquisa (SANTOS, 2007). Nesse sentido, esse procedimento foi utilizado para conhecer as opiniões dos agentes públicos em relação aos pregões, na forma presencial e eletrônica, considerando as vantagens e desvantagens destacadas nos estudos selecionados no PB.

O questionário utilizado como instrumento de coleta de dados é composto de questões abertas e fechadas endereçado aos participantes da pesquisa, identificados como agentes públicos responsáveis pelos setores de compras e/ou licitações nos municípios da região investigada. As questões fechadas apresentam as características identificadas nos estudos selecionados no PB, com uma escala Likert de cinco pontos (discordo totalmente a concordo totalmente), enquanto as questões abertas foram utilizadas para permitir a manifestação dos respondentes em relação ao tema. Para validação do questionário foi realizado um pré-teste com três servidores públicos municipais que atuam como contadores públicos, não sendo sugeridas alterações. O questionário utilizado para o levantamento está apresentado no Apêndice A, cuja aplicação ocorreu no período de setembro a novembro/2018, por meio de correio eletrônico ( $e$ mail), cujos endereços foram obtidos nos portais de transparência dos municípios. Como forma 
de tratamento e análise das respostas obtidas, foi realizada a tabulação dos dados, em planilhas do Microsoft Excel@, facilitando a análise descritiva em percentuais.

Em relação a utilização da modalidade pregão, foram realizadas consultas no endereço eletrônico do portal LicitaCon Cidadão-RS, verificando o quantitativo de processos realizados pelos municípios investigados no período compreendido de jan/2016 a set/2018. Salienta-se que a população da pesquisa é composta por 33 municípios pertencentes à Associação dos Municípios da Região Centro do Estado do Rio Grande do Sul (AMCENTRO/RS), sendo escolhida por conveniência dos pesquisadores e maior facilidade na coleta dos dados, cuja amostra é formada por 19 respondentes.

\section{RESULTADOS E DISCUSSÕES}

Quanto aos 33 municípios da região AMCENTRO/RS, inicialmente foram observados os dados divulgados no portal LicitaCon, quanto aos procedimentos licitatorios adotados nos municípios. Os dados revelam que 19 cidades não realizaram pregões eletrônicos em 2016, enquanto esse número baixou para 16 no ano de 2017, repetindo-se até set/2018. Nesse contexto, nota-se que mesmo com a indicação para o uso preferencial do pregão eletrônico, muitos municípios ainda realizam o pregão presencial em maior número.

Considerando que o objeto do estudo é o pregão nas modalidades presencial (PP) e eletrônica (PE), foram identificados no portal LicitaCon Cidadão-RS o número de pregões realizados por município. Através dos dados, observa-se que o município de Cachoeira do Sul foi o que mais realizou pregões eletrônicos em cada um dos anos pesquisados. Ao comparar o quantitativo de processos eletrônicos com o presencial, no ano de 2016 foram realizados $79,19 \%$ de processos na forma eletrônica $(n=137)$; enquanto em $2017,86,84 \%(n=165)$ e até o mês de set/2018, 59,89\% ( $\mathrm{n}=109)$. Tais dados podem sinalizar que os municípios podem enfrentar dificuldades na implantação do pregão eletrônico, conforme apresentado na Tabela 1.

Tabela 1 - Pregões realizados pelos municípios da AMCENTRO em 2016 a 2018*.

\begin{tabular}{|c|c|c|c|c|c|c|c|c|c|}
\hline \multirow{2}{*}{$\begin{array}{c}\text { Municípios } \\
\text { AMCENTRO }\end{array}$} & \multicolumn{3}{|c|}{2016} & \multicolumn{3}{|c|}{2017} & \multicolumn{3}{|c|}{ até 09/2018* } \\
\hline & $\mathrm{PE}$ & $\mathrm{PP}$ & Total & $\mathrm{PE}$ & PP & Total & $\mathrm{PE}$ & $\mathrm{PP}$ & Total \\
\hline Agudo & 5 & 21 & 26 & 5 & 25 & 30 & 3 & 23 & 26 \\
\hline Cacequi & 0 & 7 & 7 & 1 & 38 & 39 & 4 & 31 & 35 \\
\hline Cachoeira do Sul & 137 & 36 & 173 & 165 & 25 & 190 & 109 & 73 & 182 \\
\hline Capão do Cipó & 0 & 21 & 21 & 0 & 41 & 41 & 0 & 43 & 43 \\
\hline Dilermando de Aguiar & 0 & 16 & 16 & 0 & 43 & 43 & 0 & 23 & 23 \\
\hline Dona Francisca & 1 & 8 & 9 & 0 & 30 & 30 & 0 & 33 & 33 \\
\hline Faxinal do Soturno & 1 & 12 & 13 & 2 & 32 & 34 & 2 & 28 & 30 \\
\hline Formigueiro & 1 & 42 & 43 & 0 & 47 & 47 & 0 & 32 & 32 \\
\hline Itaara & 2 & 0 & 2 & 10 & 9 & 19 & 4 & 21 & 25 \\
\hline Ivorá & 0 & 39 & 39 & 0 & 76 & 76 & 0 & 44 & 44 \\
\hline Jaguari & 0 & 26 & 26 & 1 & 39 & 40 & 0 & 27 & 27 \\
\hline Jari & 0 & 19 & 19 & 0 & 32 & 32 & 21 & 31 & 52 \\
\hline Júlio de Castilhos & 29 & 44 & 73 & 17 & 39 & 56 & 18 & 39 & 57 \\
\hline Mata & 9 & 7 & 16 & 18 & 9 & 27 & 9 & 8 & 17 \\
\hline Nova Esperança do Sul & 0 & 21 & 21 & 0 & 45 & 45 & 0 & 29 & 29 \\
\hline Nova Palma & 0 & 44 & 44 & 0 & 37 & 37 & 1 & 25 & 26 \\
\hline Paraíso do Sul & 0 & 2 & 2 & 0 & 11 & 11 & 0 & 10 & 10 \\
\hline
\end{tabular}


Continuação

\begin{tabular}{|c|c|c|c|c|c|c|c|c|c|}
\hline \multirow{2}{*}{$\begin{array}{l}\text { Municípios } \\
\text { AMCENTRO }\end{array}$} & \multicolumn{3}{|c|}{2016} & \multicolumn{3}{|c|}{2017} & \multicolumn{3}{|c|}{ até 09/2018* } \\
\hline & $\mathrm{PE}$ & PP & Total & $\mathrm{PE}$ & PP & Total & $\mathrm{PE}$ & PP & Total \\
\hline Pinhal Grande & 0 & 4 & 4 & 0 & 36 & 36 & 0 & 22 & 22 \\
\hline Quevedos & 0 & 0 & 0 & 3 & 12 & 15 & 4 & 19 & 23 \\
\hline Restinga Seca & 0 & 0 & 0 & 10 & 54 & 64 & 3 & 36 & 39 \\
\hline Santa Maria & 0 & 89 & 89 & 61 & 34 & 95 & 71 & 2 & 73 \\
\hline Santiago & 1 & 44 & 45 & 0 & 71 & 71 & 0 & 21 & 21 \\
\hline São Francisco de Assis & 2 & 16 & 18 & 11 & 32 & 43 & 5 & 37 & 42 \\
\hline São João do Polêsine & 0 & 3 & 3 & 0 & 19 & 19 & 0 & 16 & 16 \\
\hline São Martinho da Serra & 0 & 0 & 0 & 0 & 6 & 6 & 0 & 13 & 13 \\
\hline São Pedro do Sul & 0 & 29 & 29 & 1 & 74 & 75 & 0 & 66 & 66 \\
\hline São Sepé & 18 & 9 & 27 & 27 & 12 & 39 & 13 & 18 & 31 \\
\hline São Vicente do Sul & 6 & 29 & 35 & 0 & 35 & 35 & 0 & 43 & 43 \\
\hline Silveira Martins & 2 & 2 & 4 & 4 & 19 & 23 & 1 & 16 & 17 \\
\hline Toropi & 0 & 6 & 6 & 0 & 33 & 33 & 0 & 27 & 27 \\
\hline Tupanciretã & 6 & 32 & 38 & 11 & 48 & 59 & 3 & 42 & 45 \\
\hline Unistalda & 0 & 0 & 0 & 0 & 20 & 20 & 0 & 17 & 17 \\
\hline Vila Nova do Sul & 0 & 3 & 3 & 0 & 7 & 7 & 0 & 6 & 6 \\
\hline Total & 220 & 631 & 851 & 347 & 1090 & 1437 & 271 & 921 & 1192 \\
\hline Total em \% & $25,85 \%$ & $74,15 \%$ & $100 \%$ & $24,15 \%$ & $75,85 \%$ & $100 \%$ & $22,73 \%$ & $72,27 \%$ & $100 \%$ \\
\hline
\end{tabular}

Fonte: Dados da pesquisa.

* Os dados dos pregões no ano de 2018 são computados de janeiro à setembro.

Ao observar o municípo de Santa Maria, no ano de 2016 foram realizados 89 pregões presenciais e nenhum na forma eletrônica. Já no ano de 2017, esse dado mudou, tendo em vista que o mesmo realizou 64,21\% dos seus processos eletrônicamente $(\mathrm{n}=61)$ e, no ano de 2018 (até setembro) foram realizados na forma eletrônica 97,26\% dos processos $(n=71)$, havendo dessa forma, um grande avanço do pregão eletrônico no município.

Outro município que se destaca é Nova Palma. Nota-se que nos anos de 2016 e 2017, o mesmo só realizou processos de compra na modalidade pregão presencial, porém, verifica-se que no ano de 2018 foi realizado o primeiro processo do município na forma eletrônica $(n=1)$. Além de Nova Palma, outros 18 municípios em 2016 não haviam realizado processos eletrônicos, representando 57,6\% dos municípios da região, enquanto os outros 14 municípios já usavam o pregão eletrônico. No ano de 2017 esse número aumentou para 16 municípios (48,5\%), mantendo-se no ano de 2018.

Conforme os dados destacados na Tabela 1, nota-se que os municípios de Capão do Cipó, Dilermando de Aguiar, Ivorá, Nova Esperança do Sul, Paraíso do Sul, Pinhal Grande, São João do Polêsine, Toropi e Unistalda não realizaram pregões eletrônicos em nenhum dos períodos analisados. Logo, os municípios de Cacequi, Dona Francisca, Faxinal do Soturno, Formigueiro, Jaguari, Quevedos, Santiago, São Pedro do Sul, São Vicente do Sul, Silveira Martins e Vila Nova do Sul estão em uma faixa de pouca representatividade do pregão eletrônico em relação ao presencial. Muitos municípios realizaram processos eletrônicos somente em um dos anos analisados ou começaram a realizar no ano de 2018.

Ao analisar a totalidade de processos licitatórios na modalidade pregão nos municípios, no ano de 2016, verifica-se que o pregão eletrônico representa $25,85 \%$, considerando o total de 851 processos. No ano de 2017 essa representatividade é de $24,15 \%$, sendo realizados 1.437 
pregões. Até set/2018, foram realizados 1.192 processos na modalidade pregão, sendo observado 22,73\% na forma eletrônica, evidenciando-se uma pequena oscilação nos percentuais em relação aos anos anteriores, mantendo-se uma tendência de queda. Nesse contexto, nota-se que há uma contradição em relação à indicação do pregão eletrônico como forma preferencial, devendo ser justificado quando não utilizada, de acordo com Tribunais de Contas e Decreto 5.450/2005, tendo em vista que muitos municípios ainda não o realizam.

Constatado o comportamento da adoção do pregão eletrônico nos municípios da região pesquisada, buscou-se as características percebidas pelos agentes públicos desses municípios por meio de questionários, com base nas afirmativas identificadas nos estudos do PB. A partir das respostas obtidas, em geral, o perfil dos respondentes é identificado como servidor público no regime estatutário $(94,7 \%)$, masculino $(57,9 \%)$, com média de idade de aproximadamente 41 anos, com ensino superior completo $(68,4 \%)$, cuja formação é administração, ciências contábeis ou direito. Complementarmente, a função de responsável pelo setor de compras e licitações nos municípios é exercida em paralelo a outro cargo ou atividade $(74,2 \%)$, destacando-se o tempo de atuação na função, superior a 10 anos (26,3\%).

Para analisar as características dos processos, o questionário traz afirmativas levantadas na literatura, para verificar a percepção dos respondentes, quanto às vantagens e desvantagens do pregão presencial e do pregão eletrônico. Nesse sentido, afirma-se que o pregão é uma ferramenta essencial para as compras públicas, identificando que $73,7 \%$ dos respondentes concordam totalmente, enquanto $26,3 \%$ concordam em partes. Observa-se que nenhum respondentes discorda da afirmação, sendo confirmada sua importância à gestão pública.

Quando perguntado se a modalidade pregão tem a finalidade de selecionar a proposta mais vantajosa à Administração e em consonância com o interesse público, 84,2\% dos respondentes concordam totalmente, ao passo que $15,8 \%$ concordam em partes. Nesse contexto, os dados corroboram com Santana e Santos (2012) quando afirmam que a modalidade pregão está em compasso com a finalidade principal da licitação, ao selecionar a proposta mais vantajosa para a Administração Pública. Ao afirmar que o pregão permite apresentação de propostas inexequíveis, 52,6\% dos respondentes discordam totalmente e 10,5\% discordam em parte, enquanto $21,1 \%$ concordam em parte e $15,8 \%$ concordam totalmente. Por conseguinte, sendo a afirmativa considerada uma desvantagem na literatura, observa-se que a partir da percepção da maioria dos respondentes, não é possível confirmar as afirmações de Niebuhr (2005), Justen Filho (2004) e Pereira (2014).

\subsection{Características do pregão presencial}

O pregão na forma presencial é a modalidade de licitação mais utilizada pela Administração Pública (MEIRELLES, 2007), confirmada por $63,2 \%$ dos respondentes que concordam totalmente e $36,8 \%$ que concordam em parte. Conforme verificado na literatura, dentre as vantagens do pregão presencial, cita-se a maior participação de empresas locais e a promoção do desenvolvimento regional, o que condiz com a opinião dos respondentes, tendo em vista que $36,8 \%$ concordam totalmente e $42,1 \%$ concordam em parte, enquanto outros $21,1 \%$ discordaram em parte. Assim, os dados empiricos confirmam a afirmação de Ramos et al. (2016) e Niebhur (2005).

De acordo com os participantes da pesquisa, o pregão presencial apresenta melhor possibilidade de negociação, considerando a relação imediata, pois o vencedor é conhecido logo após a análise da documentação. Outra vantagem se refere a maior possibilidade de esclarecimento de dúvidas em relação ao item proposto no edital, identificando que a maioria dos respondentes concordam com essa afirmação (63,2\% concordam totalmente e 36,8\% 
concordam em parte). Considerando a não dependência de conexão com internet e outros recursos tecnológicos, 53\% dos respondentes concordam totalmente e $14 \%$ concordam em parte, confirmando essa vantagem.

Quando questionados quanto às possíveis desvantagens do pregão presencial, utilizouse a afirmação sobre a menor concorrência, devido ao menor número de empresas participantes no processo, resultando que a maioria discorda totalmente $(n=7)$ ou discorda em parte $(n=5)$, o que não condiz com as afirmações de Ramos et al. (2016), Nunes (2007) e Niebhur (2005). Por sua vez, em relação à afirmação de que no pregão presencial há possibilidade de haver tumultos durante o certame, devido ao espaço fisico limitado e conflitos entre os licitantes e a comissão, $31,6 \%$ dos respondente concordam em parte e $21,1 \%$ concordam totalmente, ao passo que $21,1 \%$ discordam totalmente e $21,1 \%$ discordam em parte. A desvantagem que mais se evidenciou foi a questão relativa à lentidão do certame como um empecilho para a escolha da modalidade pregão presencial. Os resultados demonstram que 73,7\% discordam totalmente.

De acordo com o Decreto $n^{\circ} 5.450 / 2005$, os órgãos de fiscalização indicam a adoção de práticas do pregão eletrônico aos entes públicos, preferencialmente, devendo ser justificado quando utilizada outra forma. Quando questionados sobre este aspecto, 42,1\% dos respondentes discordam totalmente, $21,1 \%$ concordam em parte e $15,8 \%$ concordam totalmente. Os dados demonstram que há divergência de opiniões entre os respondentes, onde a maioria discorda (parcial ou totalmente) da imposição do pregão eletrônico como modalidade preferencial.

Contudo, ao serem indagados se o pregão presencial seria a modalidade de licitação que apresenta maior redução de gastos em relação aos demais processos de compras, observa-se que $47,4 \%$ dos respondentes concordam em parte, enquanto $31,6 \%$ são indiferentes. Os outros participantes da pesquisa dividem-se entre concordar totalmente $(10,5 \%)$ e discordar em parte $(10,5 \%)$. Estes resultados, na percepção dos respondentes, permitem inferir que o pregão presencial apresenta maior economicidade dentre as modalidades de licitação vigentes.

Para 63,2\% dos participantes da pesquisa, a sociedade pode acompanhar e fiscalizar as informações relativas aos processos licitatórios por meio do endereço eletrônico do portal de transparência do próprio município. Contudo, 57,9\% mencionam como fonte de informação o portal do LicitaCon Cidadão-RS (utilizado na pesquisa). A partir dos resultados evidenciados, apresenta-se no Quadro 3 as vantagens e desvantagens do pregão presencial, sob a ótica dos participantes da pesquisa.

Quadro 3 - Características empíricas identificadas quanto ao pregão presencial

\begin{tabular}{|l|l|}
\hline \multicolumn{1}{|c|}{ Vantagens } & \multicolumn{1}{c|}{ Desvantagens } \\
\hline Agilidade & Menor concorrência \\
\hline Economicidade & Tumultos \\
\hline Desenvolvimento regional & Qualidade do produto \\
\hline Contato direto com o fornecedor & Combinação entre os licitantes \\
\hline Transparência & Possibilidade de licitação deserta \\
\hline Maior possibilidade de entrega & Demora na realização do certame \\
\hline
\end{tabular}

Fonte: Dados da pesquisa.

No tocante às vantagens apresentadas em relação ao uso do pregão presencial, $36,8 \%$ dos respondentes mencionam que a principal é a agilidade do processo, sendo apontado na sequência a economicidade e o contato direto com os licitantes por $26,3 \%$ dos respondentes. Os resultados apontados permitem identificar que os participantes da pesquisa consideram que a melhor negociação é aquela que se realiza frente a frente com os representantes das empresas, permitindo a obtenção de menores preços. De acordo com 15,8\% dos respondentes, o pregão presencial ocorre em menos tempo, sendo a agilidade apontada como maior vantagem. Outro 
aspecto mencionado diz que o pregão presencial desenvolve as potencialidades regionais e o comércio local (10,5\%). Já a agilidade na conferência dos documentos, qualidade e garantia do bem adquirido, transparência e maior concorrência seriam vantagens do pregão presencial para $5,3 \%$ dos respondentes, o que poderia ser determinante para escolha do pregão presencial. As evidências corroboram com Soares e Possobom (2017); Ramos, Vargas, Novicki e Moraes (2016), Faria et al. (2011) e Nunes, Lucena e Silva (2007).

Em relação às desvantagens do pregão presencial, para $21 \%$ dos respondentes seria a possibilidade de discussões entre os licitantes durante o certame, corroborando com Ramos et al. (2016), Nunes (2007) e Niebhur (2005). Dos respondentes, 15,8\% concordam que outra desvantagem seria a possibilidade de combinação de preços entre os licitantes, acarretando prejuízos ao erário. Para 15,8\% dos respondentes, no pregão presencial há menor concorrência, levando-se em consideração o objeto licitado e os licitantes, não havendo maior economicidade. Outro motivo para menor concorrência seriam os privilégios para as Microempresas - ME e Empresas de Pequeno Porte - EPP, asseguradas conforme a Lei Complementar 123/2006 e suas alterações elencadas na Lei Complementar 147/2014. Com isso, licitantes enquadrados nos demais portes empresariais não podem participar de licitações exclusivas. Em relação as desvantagens do pregão presencial, $21 \%$ dos respondentes não manifestaram opinião.

\subsection{Características do pregão eletrônico}

Para o uso do pregão eletrônico é necessária atualização da equipe com cursos e treinamentos, de acordo com a maioria dos respondentes, sendo que 52,6\% concordam totalmente e outros 47,4\% concordam em parte. Ao afirmar que o pregão eletrônico proporciona maior agilidade, verifica-se que $57,9 \%$ concordam em parte e $21,1 \%$ concordam totalmente. Sobre o fato de o pregão eletrônico ser considerado uma modalidade que proporciona maior eficiência e transparência nas contratações, $52,6 \%$ dos participantes da pesquisa concordam em parte, seguidos de $26,3 \%$ que concordam totalmente. Assim, na visão da maioria dos respondentes, confirma-se a afirmação de Santana (2009) e Bittencourt (2014). A possibilidade do licitante não estar presente foi apresentada aos respondentes como uma vantagem, sendo corroborada por $52,6 \%$ que concordam totalmente, além do envio de lances e o acompanhamento do processo de forma virtual, sem a interferência dos concorrentes.

Ao investigar se o pregão eletrônico proporciona maior concorrência, considerando essa afirmação como uma vantagem à Administração Pública, 73,7\% dos respondentes concordam totalmente, corroborando com a afirmação de Santana (2009) e Barros (2005). Porém, no que tange as desvantagens do pregão eletrônico, conforme identificado no PB, cita-se os atrasos na entrega dos produtos, devido à distância das empresas fornecedoras, confirmado por 36,8\% dos respondentes, que concordam totalmente, e outros $42,1 \%$ que concordam em parte, enquanto $5,3 \%$ discordam em parte e $15,8 \%$ discordam totalmente.

Quanto à necessidade de conexão com internet de boa qualidade durante o processo, quase a totalidade dos respondentes concorda totalmente com a afirmação (89,5\%), demonstrando a dependência da tecnologia para realização do certame. Por outro lado, quando verificada a desvantagem em relação ao contato indireto com os fornecedores, que dificultaria a negociação, $31,6 \%$ concordam totalmente e $26,3 \%$ concordam em parte.

De acordo com a opinião dos respondentes, identifica-se que 31,6\% concordam totalmente e 31,6\% concordam em parte que não há maior demora no envio dos documentos de habilitação, visto que os mesmos são encaminhados eletronicamente. Contudo, 5 respondentes discordam em parte e 2 discordam totalmente, presumindo-se que há demora em alguns casos. Por outro lado, a afirmação de que o pregão eletrônico permite maior número de concorrentes, 
assegurando melhores preços para a Administração Pública, resultou em 57,9\% dos respondentes que concordam totalmente e $31,6 \%$ que concordam em parte, corroborando as afirmações levantadas.

Depois de observar os resultados apontados pelos respondentes quanto às características do pregão, confrontando a percepção dos responsáveis pelo setor de compras dos municípios investigados, foram realizadas questões abertas em que os respondentes deveriam mencionar as razões que justificam a realização do pregão presencial e/ou eletrônico. Tendo em vista que os respondentes poderiam apontar diversos motivos para o fato, o somatório das respostas pode exceder a $100 \%$. Para fins de análise, as respostas foram transcritas e categorizadas para identificar um padrão.

Conforme observado, 42,1\% dos respondentes disseram que realizam a modalidade pregão na forma eletrônica devido à economicidade gerada ao município, tendo em vista melhores negociações com os licitantes e almejando o menor preço. A segunda razão apontada se refere a transparência durante todo o processo, sendo a resposta de $36,8 \%$ respondentes. Para $31,6 \%$ dos respondentes a praticidade proporcionada pelo pregão, seja presencial ou eletrônico, é outro critério relevante para sua escolha, tendo em vista as demais modalidades licitatórias. Já para 26,3\%, o pregão proporciona maior agilidade ao processo, considerando editais menos complexos e celeridade, desde a sua elaboração até seu término, facilitando a tramitação.

Com relação ao pregão eletrônico, na percepção de 78,9\% dos respondentes, a principal vantagem é a amplitude concorrencial, pois em muitos casos os bens não são encontrados regionalmente, diminuindo o número de licitações desertas. Da mesma forma, há maior concorrência e economia para a Administração Pública, conforme 26,3\% dos respondentes. A celeridade do certame, considerando que os licitantes não precisam estar presentes, seria uma vantagem para $21 \%$ dos respondentes, enquanto a agilidade do processo, redução do espaço físico, são apontados por 10,5\% dos respondentes, e a aumento da transparência, para 5,3\%. Apenas 2 participantes da pesquisa não apontam vantagens do pregão eletrônico, justificando que o seu município não pratica tal processo.

No Quadro 4 é possível observar as categorias identificadas quanto às vantagens e desvantagens do pregão eletrônico, consideração a percepção dos participantes da pesquisa.

Quadro 4 - Categorias identificadas quanto ao pregão eletrônico

\begin{tabular}{|l|l|}
\hline \multicolumn{1}{|c|}{ Vantagens } & \multicolumn{1}{c|}{ Desvantagens } \\
\hline Ampla concorrência & Demora ou não entrega do produto \\
\hline Economicidade & Qualidade do produto \\
\hline Agilidade & Envio da documentação eletronicamente \\
\hline Celeridade & Distância (troca de produtos) \\
\hline Transparência & Dependência da internet \\
\hline
\end{tabular}

Fonte: Dados da pesquisa.

No tocante às desvantagens do pregão eletrônico, 31,6\% dos participantes acreditam que a principal seria a demora ou não entrega dos produtos, tendo em vista a distância das empresas em relação a localização do município e, por consequência, a dificuldade de contato. Para 15,8\% são desvantagens a qualidade do produto, não conhecer o fornecedor e demora no envio dos documentos para habilitação, em especial nas empresas que ganham poucos itens. Demora na verificação dos documentos de habilitação é outra desvantagem para $10,5 \%$ dos respondentes. Já para 10,5\% dos participantes a desvantagem do pregão eletrônico diz respeito à questões estruturais, como a possibilidade de faltar luz, dependência de internet, problemas com trocas de mercadorias e a não participação de empresas locais no certame, levando em 
consideração que as plataformas utilizadas cobram um percentual dos fornecedores sobre o valor da compra, o que para muitas eleva o custo do produto. Não se obteve respostas em relação às desvantagens do pregão eletrônico de 2 respondentes, sendo que um afirma não haver desvantagem e outro não conhecer a prática do pregão eletrônico.

\section{CONSIDERAÇÕES FINAIS}

Ao considerar que os processos licitatórios são obrigatórios para aquisições de bens e serviços, tendo como principal objetivo selecionar a proposta mais vantajosa à Administração Pública, admite-se que o pregão atende a este fim. Para que esse processo seja bem-sucedido, faz-se necessário que desde a fase interna (elaboração do edital) até sua homologação, seja conduzida por servidores que atendam aos princípios norteadores da Administração Pública. Contudo, estes precisam ser devidamente capacitados e treinados para a condução das práticas licitatórias, conforme a legislação disciplinadora do processo.

Dentre as modalidades de licitação, o pregão é considerado por muitos pesquisadores a modalidade mais ágil, tendo em vista a inversão de fases do processo, possibilitando a aquisição de bens e serviços comuns através de sucessivos lances, tornando o processo mais célere e gerando maior economia aos cofres públicos (ALMEIDA; SANO, 2018). Nesse contexto, notase que o pregão transformou as compras públicas, trazendo inovações, com características próprias e que podem ser apontadas como vantagens e desvantagens. A partir dos resultados evidenciados, verifica-se que a maioria dos municípios investigados nessa pesquisa não utiliza o pregão eletrônico, identificando o pregão presencial como alternativa. No entanto, a partir das características identificadas nos estudos anteriores, apresentou-se aos gestores públicos para confrontação da prática, levando-se em consideração as necessidades da gestão pública.

O presente estudo constatou que o pregão eletrônico é particularizado, uma vez que todo o processo ocorre por meio da internet, aumentando a concorrência e possibilitando a participação de empresas de diferentes localidades. Logo, a distância entre o órgão público e os licitantes não é considerada uma desvantagem, porém outros impasses podem ser percebidos, tais como: atraso na entrega dos produtos, dificuldades na troca de mercadorias, demora para o envio dos documentos de habilitação e difícil contato com as empresas fornecedoras (NUNES, 2007; RAMOS, et al., 2016). Já o pregão presencial é um processo mais eficiente, conforme os participantes da pesquisa, possibilitando conhecer os fornecedores e isso, para alguns gestores públicos, é uma maneira de obter melhores preços na aquisição de bens e serviços. Por outro lado, tal proximidade pode resultar em possíveis fraudes e corrupção.

Com base no exposto, entende-se que a modalidade pregão tornou o processo de compras públicas mais transparente, possibilitando selecionar a proposta mais vantajosa, trazendo mais agilidade, eficiência nas contratações e proporcionando economia ao erário público, viabilizando a qualquer cidadão a averiguação dos atos praticados pelos gestores e em tempo real. Destaca-se que o estudo alcançou seu objetivo de verificar as características do pregão presencial e eletrônico, sob a ótica dos gestores públicos municipais, sendo evidenciadas suas vantagens e desvantagens. Assim, conclui-se que a indicação de uso preferencial do pregão eletrônico ainda não é cumprida por muitos municípios, pois há dificuldades operacionais e tecnológicas, além das desvantagens evidenciadas pelos gestores públicos.

O estudo teve como limitações o baixo número de respondentes e a demora no retorno dos participantes da pesquisa. Por tais motivos, sugere-se para futuros estudos a realização de uma pesquisa com uma amostra maior de participantes, considerando os constructos evidenciados nesse estudo e que podem contribuir para explicar a implantação e uso do pregão nos municípios, bem como realizar estudos comparativos entre municípios de diferentes regiões 
ou estados, confrontando com os achados nessa pesquisa. Espera-se que esses resultados possam contribuir aos demais gestores públicos no planejamento das ações para implantação e superação das desvantagens do pregão, oportunizando maior economicidade e celeridade dos processos e melhoria na qualidade da gestão pública.

\section{REFERÊNCIAS}

ALMEIDA, A. A. M.; SANO, H. Função compras no setor público: desafios para o alcance da celeridade dos pregões eletrônicos. Revista de administração pública, v. 52, n. 1, p. 89$106,2018$.

ARAÚJO, D. D. Pregão Aprendendo na Prática. Rio de Janeiro: Algo a Dizer, 2006.

BARROS, M. S. 502 comentários sobre licitações e contratos administrativos. São Paulo: Editora NDJ, 2005.

BITTENCOURT, S. Licitação Passo a Passo. 7.ed. Rio de Janeiro: Fórum, 2014.

BRASIL. Constituição da República Federativa do Brasil. Brasília, DF, 1988.

Decreto n. 5.450. Regulamenta o pregão na forma eletrônica e dá outras providências. Ministério do Planejamento, Orçamento e Gestão, Brasília, DF, 2005.

Lei n. 8.666. Regulamenta o art. 37, inciso XXI, da Constituição Federal, institui normas para licitações e contratos da Administração Pública, e dá outras providências. Senado Federal, Brasília, DF, 1993.

Lei n. 10.520. Institui, no âmbito da União, Estados, Distrito Federal e Municípios, a modalidade de licitação denominada pregão, para aquisição de bens e serviços comuns, e dá outras providências. Senado Federal Brasília, DF, 2002.

CARVALHO FILHO, J. S. Manual de direito administrativo. 25.ed. São Paulo: Atlas, 2012.

FARIA, E. R.; FERREIRA, M. A. M.; SANTOS, L. M.; SILVEIRA, S. D. F. R. Pregão eletrônico versus pregão presencial: estudo comparativo de redução de preços e tempo. Revista de Contabilidade do Mestrado em Ciências Contábeis da UERJ, v. 16, n. 1, p. 47-61, 2011. [PB6]

FERNANDES, J. U. J. Sistema de Registro de Preços e Pregão Presencial e Eletrônico. 3.ed. Belo Horizonte: Fórum, 2009.

JUSTEN FILHO, M. Comentários à Lei de Licitações e Contratos Administrativos. 5.ed. São Paulo: Malheiros, 2004.

KOHAMA, H. Contabilidade Pública: Teoria e Prática. 14.ed. São Paulo: Atlas, 2014. MEIRELLES, H. L. Licitação e Contrato administrativo. 14.ed. São Paulo: Malheiros, 2007. 
NIEBUHR, J. M. Pregão Presencial e Eletrônico: De acordo com o Decreto 5.450/05.

Curitiba: Zênite, 2005.

NUNES, N. Pregão presencial e eletrônico: vantagens e desvantagens um estudo de caso com os pregoeiros da UFSC. Dissertação - Universidade Federal de Santa Catarina. Florianópolis, 2007. [PB9]

NUNES, J.; LUCENA, R. L.; SILVA, O. G. Vantagens e desvantagens do pregão na gestão de compras no setor público: o caso da Funasa/PB. Revista do Serviço Público, v. 58, n. 2, p. 227, 2007. [PB10]

PEREIRA, B. C. Vantagens e Desvantagens do Pregão na Administração Pública.

Monografia - Curso de Pós-Graduação em Gestão Pública. Universidade Candido Mendes, Rio de Janeiro, 2014. [PB4]

RAMOS, J.; VARGAS, J.; NOVICKI, A.; MORAES, D. R. As Vantagens e Desvantagens do Pregão Eletrônico e Presencial do Ponto de Vista da Administração Pública. Revista de Administração e Contabilidade-RAC, v. 15, n. 29, 2016. [PB3]

RAUSCH, R. B.; SOARES, M. Controle social na administração pública: a importância da transparência das contas públicas para inibir a corrupção. Revista de Educação e Pesquisa em Contabilidade (REPeC), v. 4, n. 3, p. 23-43, 2010. [PB7]

SANTANA, M. N. C.; SANTOS, C. S. Restrições da utilização da modalidade de licitação pregão. Gestão \& Planejamento-G\&P, v. 12, n. 2, 2012. [PB5]

SANTOS, R. dos S. Metodologia científica: a construção do conhecimento. Rio de Janeiro: Lamparina, 2007.

SANTOS, V. M. A Lei do Pregão no Município: Uma Visão Prática e Operacional. Porto Alegre: Verbo Jurídico, 2008.

SCHEREN, G.; WESCINSKI, J. V.; BARICHELLO, R. Análise do processo de compras do setor público dos municípios com a maior população do estado de Santa Catarina. Revista Capital Científico, v. 15, n. 4, 2017. [PB1]

SILVA, L. M. Contabilidade Governamental: Um Enfoque na Contabilidade Municipal. São Paulo: Atlas, 2003.

SLOMSKI, V. Manual de contabilidade pública: um enfoque na contabilidade municipal: de acordo com a Lei de Responsabilidade Fiscal. 2.ed. São Paulo: Atlas, 2003.

SOARES, C. S.; POSSOBOM, G. L. V. A participação das pequenas empresas nas compras públicas e o desenvolvimento local em um pequeno município do RS. Revista Estratégia e Desenvolvimento, v. 1, n. 1, 2017. [PB2]

SOBRAL, P. V. N. C.; NETO, R. S. O Pregão Eletrônico Como Ferramenta De Eficiência Na Gestão Pública. Journal of Profess. Bus. Review, v. 5, n. 1, 2020. 
SOUZA, W.; TEIXEIRA, A. J. C. Um estudo sobre a viabilidade de implantação do pregão eletrônico e uma contribuição na apuração dos resultados nos processos licitatórios. Revista de Educação e Pesquisa em Contabilidade, v. 2, n. 2, p. 75-94, 2008. [PB8]

VALMORBIDA, S. M. I.; ENSSLIN, L. Construção de conhecimento sobre avaliação de desempenho para gestão organizacional: uma investigação nas pesquisas científicas internacionais. Revista Contemporânea de Contabilidade, v. 13, n. 28, p. 123-148, 2016.

VASCONCELOS, G. G. V. A Garantia Constitucional da Licitação na Modalidade Pregão na Forma Eletrônica. Direito Público, v. 3, n. 13, 2006.

\section{APÊNDICE A - QUESTIONÁRIO}

Bloco 1 - PERFIL DOS RESPONDENTES:

1) Gênero: $F($ ) $M($ )

2) Idade: anos

3) Maior titulação/formação escolar:

( )Ens. Fundamental; ( )Ens. Médio; ( )Ens. Sup. Incompleto em

( )Ens. Sup. Completo em

( )Pós-graduação em

( ) Mestrado em

( ) Doutorado em

4) Município:

5) Regime: ( )Estatutário; ( )Celetista; ( )Cargo de Confiança; ( ) outros:

6) Função:

7) Tempo do exercício na instituição:

8) Tempo do exercício na área de compra públicas e/ou licitação:

Bloco 2 - Características do Pregão:

9) Em relação à modalidade de licitação pregão, analise conforme sua percepção:

( )Discordo totalmente ( )Discordo em parte ( )Indiferente ( )Concordo em parte ( )Concordo totalmente

9.1) O pregão é uma ferramenta essencial para as compras públicas.

9.2) A modalidade pregão tem a finalidade de selecionar a proposta mais vantajosa para a Administração, e em consonância com o interesse público.

9.3) Uma vantagem do pregão frente às demais modalidades é não haver limite de valores para contratação, desde que o objeto licitado seja a aquisição de bens e/ou serviços comuns.

9.4) O pregão apresenta maior economia ao erário, permitindo aos licitantes ajustes da proposta, onde a competitividade aumenta e os preços ofertados inicialmente reduzem.

9.5) O processo de compra na modalidade pregão apresenta maior transparência, permitindo o conhecimento das propostas entre os participantes, governo e a sociedade, não havendo manipulação de resultado;

9.6) O pregão permite a Inversão de fases, simplificando significativamente os procedimentos licitatórios, havendo menos burocratização e maior celeridade.

9.7) O pregoeiro e sua equipe apresentam maior rigor na análise de determinadas empresas;

9.8) O pregão permite a apresentação de propostas inexequíveis.

9.9) A limitação do pregão aplicável apenas para aquisição de bens e serviços comuns, poderia ser revista, sendo estendido aos demais tipos.

9.10) Há dificuldades em classificar os bens e serviços comuns. 


\section{Bloco 3 Pregão presencial:}

10) Em relação ao pregão presencial, analise as afirmações conforme sua percepção:

( )Discordo totalmente ( )Discordo em parte ( )Indiferente ( )Concordo em parte ( )Concordo totalmente

10.1) O pregão presencial é a modalidade de licitação mais comumente utilizada pela Administração Pública.

10.2) O pregão presencial caracteriza-se pela maior participação de empresas locais e promoção do desenvolvimento regional;

10.3) Há melhor negociação entre os licitantes, tendo em vista a negociação imediata, pois o vencedor é conhecido logo após a análise da documentação;

10.4) Há maior possibilidade de esclarecimentos de dúvidas em relação ao item proposto no edital no pregão presencial.

10.5) O pregão presencial apresenta como vantagem a não dependência de conexão com internet e outros recursos tecnológicos.

10.6) O pregão presencial apresenta como desvantagem menor concorrência, devido ao menor número de empresas participantes no processo.

10.7) Como desvantagens do pregão presencial são citadas as possibilidades de tumultos durante o certame, espaço físico limitado e Discussões e conflitos entre licitantes e comissão.

10.8) A lentidão do certame é um empecilho para a seleção da modalidade pregão presencial.

10.9) A realização do pregão na forma eletrônica deve ser obrigatória, devendo o pregão presencial ser realizado nos casos em que é comprovada a inviabilidade da realização eletrônica.

10.10) O pregão presencial é a modalidade de licitação que apresenta maior redução de gastos dos processos de compras.

\section{Bloco 4 - Pregão Eletrônico}

11) Em relação ao Pregão Eletrônico, analise as afirmações conforme sua percepção:

( )Discordo totalmente ( )Discordo em parte ( )Indiferente ( )Concordo em parte ( )Concordo totalmente

11.1) Para uso do pregão eletrônico é necessário atualização da equipe com cursos e treinamentos.

11.2) O pregão eletrônico proporciona maior agilidade no processo de compra.

11.3) O pregão eletrônico proporciona maior eficiência e transparência nas contratações.

11.4) Uma vantagem do pregão eletrônico refere-se ao licitante não estar presente fisicamente, possibilitando o envio de lances e o acompanhamento do processo de forma virtual, sem interferência dos concorrentes nas cotações;

11.5) O pregão eletrônico traz mais economicidade aos cofres públicos;

11.6) Você concorda que no pregão eletrônico há uma grande concorrência e, que isso seria considerado uma vantagem para a administração pública;

11.7) Uma desvantagem do pregão eletrônico é a demora, pois, na maioria das vezes, há atrasos na entrega dos produtos, conforme edital, em razão da distância das empresas;

11.8) Para o uso o pregão eletrônico, durante todo o processo, necessita-se de uma internet de boa qualidade;

11.9) Uma desvantagem do uso do pregão eletrônico é o contato indireto com o fornecedor, que causa dificuldades na negociação;

11.10) Há demora para o envio dos documentos de habilitação, visto que os mesmos devem ser enviados via Correio;

11.11) O pregão eletrônico permite um maior número de concorrentes, assegurando melhores preços.

\section{Bloco 5 - PERGUNTAS ABERTAS:}

1) Por que o seu município utiliza o pregão presencial e/ou eletrônico?

2) Quais são as formas utilizadas pelo seu município para promover treinamento e atualização sobre compras públicas?

3) Como a sociedade pode acompanhar/fiscalizar as informações relativas aos processos licitatórios?

4) Na sua opinião, quais são as vantagens do pregão presencial?

5) Na sua opinião, quais são as desvantagens do pregão presencial?

6) Na sua opinião, quais são as vantagens do pregão eletrônico?

7) Na sua opinião, quais são as desvantagens do pregão eletrônico? 